\title{
A Framework For Virtual Leadership Development In The Intelligence Community
}

\author{
Jacob R. Jenkins, Ed.D \\ Executive Director of Executive Education \\ Georgetown University, McCourt School of Public Policy
}

\begin{abstract}
The purpose of this paper is to develop a set of elements that Intelligence Community (IC) leadership can use as a framework to transition leadership development courses from the current face-to-face format to the virtual environment. IC employees face unique leadership challenges, and broader application of leadership development is needed. Due to the unique ethical and leadership dilemmas faced by the IC workforce, the unique makeup of the current labor force, the limitations of traditional face-to-face leadership development efforts, and the broad group of stakeholders affected, the IC should transition from face-to-face leadership development to a virtual environment. In this phenomenological qualitative study, eight primary themes emerged as important to include in a virtual leadership development course.
\end{abstract}

\section{INTRODUCTION}

Background of the Problem. Intelligence professionals routinely face unique and challenging ethical dilemmas (Godfrey \& Jacobs, 1978; Allen, 2008; Goldman, 2006). Often concealed from public scrutiny and debate, leaders of the Intelligence Community (IC) must make decisions and gather information in a way that assists the government in protecting the homeland, while also protecting the rights and liberties of individuals (Perry, 1995). Although intelligence forces have become an integral part of the current government (Herman, 1999), decision makers within those organizations are faced with vague statutory authorities that could be perceived by the public as overreaching (Clark, 2010).

Traditional leadership development methods have largely targeted those already in leadership positions, while future managers in the IC will likely emerge from the lower ranks of its organizations. Because of this, leadership development that is aimed at the needs of all generations is necessary. The effectiveness of leadership development efforts in the IC impacts policy makers, employees, managers, and other public officials. Therefore, leadership development resources must be available to those within the IC at all levels of command and responsibility.

Purpose of the Study. Leadership development skills are defined as individual strengths such as influencing, relationship building, strategic thinking, and executing (Rath \& Conchie, 2008). Face-to-face leadership development courses provided by IC agencies to employees is costly and therefore limits the number of employees who can participate in the training. IC employees are faced with unique leadership challenges, and broader administration of leadership development is needed. Unprecedented budget cuts, broad technological advances, and a 
workforce that spans five generations within the IC have created an environment where the traditional methods of leadership development training need to change (Clapper, 2013). This research will focus on shifting leadership development training to a new format. This change will allow broader administration of current training curriculum, while also using existing IT infrastructure to reduce cost. Previous research indicates that training topics typically reserved for face-to-face environments are suitable for a virtual setting (Liebowitz, 2003; PainterMorland, Fontrodona, Hoffman, \& Rowe, 2003; Bos \& Shami, 2006). The purpose of this paper is to develop a set of pedagogical attributes or delivery techniques, hereafter referred to as elements, that IC leadership can use to transition current curriculum from face-to-face to the virtual environment.

Research Question. What elements should be included in a virtual leadership development course for IC employees?

Significance of the Study. Organizations that operate within the framework of the IC face difficulties in accessing leadership development resources on the open Internet, as many agencies operate on a classified network that cannot access external resources (Director of Central Intelligence, 2002). For several years, employees within the IC have indicated that they are satisfied with the trust and confidence of their senior management, but have also stated that they wish to see increased leadership in areas such as motivation and commitment (Office of the Director of National Intelligence, 2008). Employee insight into leadership and vision, as well as investigations conducted by the Inspector General of the Office of the Director of National Intelligence (ODNI), caused a renewed interest in examining leadership development within the IC agencies (Maguire, 2008). While surveys and reports indicated that leadership characteristics were low, there was no effort made to define adequate metrics (Office of the Director of National Intelligence, 2008). The ethical dilemmas that intelligence officers face are unique and numerous. Intelligence officers have access to significant amounts of sensitive information that the rest of society does not have access to, and to use that information to its maximum capability to protect the homeland and defend against those who wish to do it harm (Herman, 1999). Along with the difficulties of acting within the bounds of the law when operating in the intelligence environment, those within the IC also often face an enemy that uses corrupt or misguided intelligence (Herman, 1999). Additionally, IC employees are often faced with a unique dilemma of providing an accurate representation of the facts to their superiors and policymakers; all while using deceitful or uncomfortable tactics to extract truth from their adversaries (Godfrey, 1978; Herman, 1999). These challenges contribute significantly to the need to have strong leaders in the IC, and leadership training for their development. While the Federal Government has used virtual courses to train their employees in job skills, the virtual environment has not often been used as a tool for leadership development ("National Security: An Overview of Professional Development Activities Intended to Improve Interagency Collaboration," 2010). There is an abundance of existing research on the methods and frameworks for leadership development within the public sector, yet the mode has been widely ignored.

The government and intelligence officials have recognized that if they are to protect and defend the homeland effectively, communication and information sharing are critical to the effective execution of their mission (Monahan, 2011). Not only would relationships and information sharing improve with a greater emphasis on leadership development within the IC, 
but also intelligence gaps could be prevented by a culture where interaction between leaders and followers is transformed.

Unique leadership challenges point to a need for a more robust and broad leadership development effort in the IC. In 2006 the Director of National Intelligence released a strategic human capital plan that indicated that a majority of IC employees were not satisfied with leadership practices within their organization between the years 2001 and 2005 (Office of the Director of National Intelligence, 2006). While public officials have recognized this, little advancement has been made in correcting such a deficit. Budget limitations and mission needs have only further subdued any progress in furthering leadership development efforts, as the limited technical environment within the IC confines the opportunity for delivering relevant and on-demand leadership development resources to the workforce. With several generations working alongside each other in today's workplace, traditional leadership training programs provided by the Federal Executive Institute are costly and time-consuming (Center for Leadership Development, n.d.). What is more, traditional leadership development methods have largely been targeted towards those already in leadership positions. With the future managers in the IC likely coming from the lower ranks of its organizations, leadership development that is intended for all generations is needed. To understand this problem, and identify actionable solutions, an understanding of those affected by the leadership development issues with the IC is necessary. The workforce, policymakers, those in the private sector, and the international community all have a stake in the decisions made by leaders within the IC.

Stakeholders. The leadership development deficit within the IC related to the intelligence shortfalls and employee feedback goes beyond just those within the IC workforce. Public organizations, such as the IC, are uniquely positioned as entities that are responsible to the taxpayer for providing a service for social or defense needs. These organizations are responsible for providing this in a way that is ethical and, especially in recent times of budgetary crisis, delivered in an efficient manner.

For those in the IC, there are several layers of stakeholders, many of whom organizations in the IC are accountable (Randol, 2010). Public outcry and significant media coverage demonstrate just how broad the impact leadership decisions within the IC are (Ball \& Rusche, 2013). Policymakers, including the President, Congress, and agency directors, are appointed on behalf of the people to make decisions that will assist in the assurance of their security and economic stability. To some, the positions of these policymakers are contingent upon how successful the public perceives that they have been in providing this service (Burden \& Hillygus, 2009). These policy makers are not just those in elected offices, such as the President or Congress, but the political appointees tasked with leading major IC organizations, such as the Director of National Intelligence, the Attorney General, and the directors of the seventeen IC agencies. These stakeholders that hold public office have not only committed to ensuring the safety and security of citizens, but they will also be tremendously affected by the decisions made by those under their command. Particularly for those in high-profile positions that receive a significant amount of media attention, their careers are also directly impacted by leadership decisions. 
The employees of the IC organizations are those who not only feel a sense of public calling to serve their country, but they are also accountable to the policymakers and citizens. They are also considered stakeholders in that they have a vested interest in their careers and the leadership opportunities offered by their employers. Managers, while still considered employees of the IC organizations, have a particular responsibility to provide ethical leadership based on the position of trust that's been placed on them by policymakers and the by U.S. citizens. When considering employees as stakeholders, leadership development is often touted as a means to empower employees. There is research that suggests employees respond positively to empowerment, and in particular feel a greater sense of motivation (Bartol \& Locke, 2006).

Leadership decisions in the IC have a direct impact on the relationships the U.S. has with critical foreign partners (Walsh, 2007). In 2013, news broke that the NSA had been intercepting data from Germany's Chancellor Angela Merkel (Parmar, Miller, and Ledwidge, 2014). The aftermath of this international-relations scandal culminated in Merkel stating that trust between the two nations must be rebuilt (Parmar, Miller, and Ledwidge, 2014). What is more, the Wall Street Journal reported that the U.S. was conducting surveillance on some thirty-five world leaders (Gorman \& Entous, 2013).

Each of these entities is considered stakeholders based on a set of often mutual impacting factors that will be discussed in the following pages of this paper, and each results from the consequences of an IC organizations action or inaction as it relates to leadership development and the policies that govern that leadership development process. These factors include morale, productivity, cost savings, and national security (Weakliem \& Finkel, 2006; Pellerin, 2013). While these four factors are not exhaustive, they represent a substantial group of linked consequences that may occur in the field of intelligence and national security (see figure 1 below) without the proper leadership development policy. 


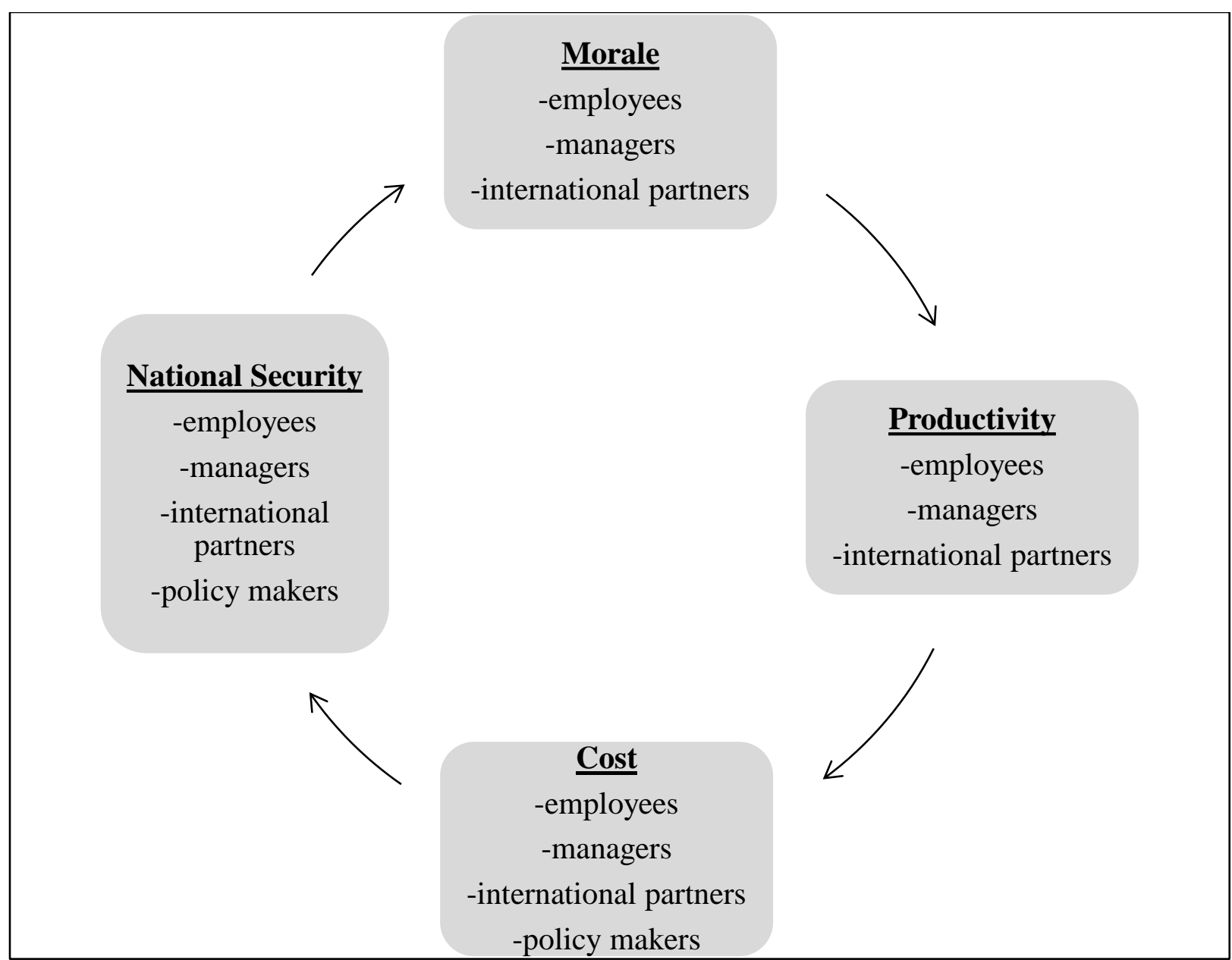

Figure 1. Linked consequences of leadership development within the Intelligence Community

While there may be an initial reaction that leadership development will consume a significant amount of cost for government organizations, we see that there are significant costs associated with ethical failures in both the private and public sector. While many of the major business failures in the early 2000s that were a springboard for the United States' current financial woes seemed to involve fundamental business errors, the roots of many of these cases involved substantial and well-documented ethical failures. These failures include those associated with Enron and WorldCom ("The Good, the Bad, and Their Corporate Codes of Ethics: Enron, Sarbanes-Oxley, and the Problems with Legislating Good Behavior," 2003). There are various levels of costs associated with unethical behavior that stems from a lack of leadership; some of these consequences include administrative and audit costs, legal and investigative costs, remedial education, and employee turnover (Thomas, Schermerhorn, Dienhart, \& Bartles, 2004).

There is also a sense of public appearance that plays a role in the cost factors of unethical behaviors. As IC agencies work with foreign partners to leverage shared resources, there may often be a sense of political pressures that other nations feel when they align with organizations with poor reputations. As one scholar put it, "... the value of ethical behavior resides in the fact 
that it signals to others that we are trustworthy, and, hence, a good partner to do business with." (Schwab, 1996, p. 499). This issue of public appearance will also play a significant role in how citizens perceive the level at which their civil liberties are being protected and respected. The leadership and ethical decisions, which lead to cost issues, can have a direct effect on national security. These costs include acquisition reductions that involve the development and procurement of weapon systems, lower development capabilities for the US defense industry, and a substantial reduction in force of the military, intelligence, and defense organizations (Bosserman, 2011).

\section{LITERATURE OVERVIEW}

Virtual Learning. The growing availability of the World Wide Web to individual consumers created a new market for educational institutions (Patel \& Patel, 2006). As institutions, both for-profit and traditional, realized the current and potential benefits of virtual education, the movement quickly spread. This boom in the virtual education market is evidenced by the rapid arrival of virtual course management software packages in the early years of virtual education. For example, by 2004, over 110 virtual course management software packages were on the market, and in 2015 there were over 450 major virtual learning software packages representing a $\$ 56$ billion industry (Kim, 2004; McIntosh, 2015). Some of the U.S.'s most reputable institutions, such as Harvard and Duke Universities, were among the first to participate in graduate school virtual learning (Patel \& Patel, 2006). With the quick expansion of virtual learning, it is important to understand if the convenience and flexibility translate to effective learning. When virtual courses are created using pedagogically sound practices, they provide similarly effective learning environments (Driscoll, Jicha, Hunt, Tichavsky, \& Thompson, 2012). Early and current research indicates that there is no significant difference between the quality of face-to-face and virtual education (Kingma \& Keefe, 2006; Ya Ni, 2013).

In 2012 a 13-year study that evaluated the outcomes of learners in both a virtual and faceto-face American government course revealed that differences in learning outcomes between the two formats were insignificant (Botsch \& Botsch, 2012). The study covered over 3,000 students from, discovered that neither format displayed a distinct advantage. Research conducted by Ya Ni (2013), which surveyed 96 institutions affiliated with the National Association of Schools of Public Affairs and Administration (NASPAA), also suggests that participation in virtual public administration courses are less intimidating, and the value and extent of interaction in the virtual format may be improved. The study did note that research methods courses may prove difficult in the virtual format.

Action Learning. There is evidence that there are benefits in the use of action learning programs as a means "to develop specific, self-selected leadership skills, and acquire greater effectiveness in building teams and handling problems" (Raudenbush \& Marquardt, 2008). Marquardt (p. 3, 2004) describes action learning as "a human resource development tool that simultaneously solves problems and develops leaders and teams." The primary focus of action learning is to place managers in real situations and to ask appropriate questions in that

environment. There is a strong emphasis not only on what the manager is learning but how they learn, as well as the context of the learning (Raudenbush \& Marquardt, 2008). 
Managers in classroom facilitated leadership development courses are often passive and lack energy (Raudenbush \& Marquardt, 2008). An action-learning framework may prove beneficial for this sort of learner. The observation that managers may not be active and energized in virtual leadership development training may not hold true when action-learning is a central piece of the learning framework.

Virtual Learning Course Attributes. Research suggests that simulated role-playing activities are a critical element, and a step-by-step framework for selection of exercises, simulation preparation, roles, and techniques of a simulation are important (Wedig, 2010). This framework was applied to virtual, face-to-face, synchronous, and asynchronous, distributed and single classroom, and individual and team formats. The results of the study suggest that given that time and technology resources are available, the virtual asynchronous approach to simulation may be the best option to achieve desired levels of learning (Wedig, 2010).

Simulation is needed in asynchronous virtual learning, and research suggests that this format may be better than in-person learning (Wedig, 2010). This research goes beyond whether virtual learning is feasible, and asks whether it is best. While further research is needed to answer this additional question, the achievements met in Wedig's virtual framework give further evidence that virtual learning is an acceptable leadership development model.

Focusing on the effects of self-regulated virtual learning in organizational settings, some categorize personal versus social learning strategies and develop measurement scales to do so (Wan, Campeau, \& Haggerty, 2012). Such research suggests that self-regulated learning strategies are needed in virtual learning. The variables used, goal orientation, virtual competence, and intellectual demands, are used to measure how learners in a virtual environment who adopt different self-regulated learning strategies have differing outcomes. These findings not only indicate that self-regulated learning strategies are needed but also gives assistance to virtual learners on obtaining improved learning outcomes through their use of various learning strategies (Wan et al., 2012).

In examining the relation to the author's research and dissertation theme of attributes needed in virtual courses, this research offers valuable information for groups that use or plan to use virtual learning (Wan et al., 2012). Feedback, the formative assessment in learning environments that allows learners to give and receive input on the progress of their learning, is essential to successful virtual courses (Espasa \& Meneses, 2009). Previous research that focuses on three aims (identifying the presence of feedback, characterizing feedback, and explore relationships between feedback and results) suggests that the best markers to determine the success of feedback are student satisfaction and final grades (Espasa \& Meneses, 2009).

Makeup of the Current Workforce. Today, four, and possibly five, generations work side-by-side in the workplace: Traditionalists (born 1900-1945), Baby Boomers (born 19461964), Generation Xers (born 1965-1980), and Millennials ((born 1981-1999) Raines, 2003). According to the U.S. Department of Labor, the population of 65- to 69-year-olds in the workforce is expected to increase by $37 \%$ between 2010 and 2020, and workers 70 years old and over will rise by $38 \%$ from 24.6 to 31.8 million (Lerman \& Schmidt, n.d.). Such a mix of ages 
presents a diverse set of views on values and communication that inform an organization as to how it should design and deliver training (Myers \& Sadaghiani, 2010).

Considering these characteristics, and how to augment various strengths and weaknesses in each generation, is vital to the success of virtual leadership training. Millennials, for example, tend to work well in teams, are motivated by the impact they have on their organization, prefer a more open and frequent communication channel with their superiors, and are comfortable using technology in how they communicate (Myers \& Sadaghiani, 2010). While the previously stated research indicates that Millennials are more comfortable with communicating using technology, Baby Boomers are more likely to identify key information presented on web-based communication (Djamasbi, Siegel, Skorinko, and Tullis, 2011). There are several characteristics in each generation that should be considered, as indicated in figure 2 below when designing virtual leadership development that targets the broader workforce.

\begin{tabular}{|c|c|c|c|}
\hline Traditionalists & Baby Boomers & GenXers & Millennials \\
\hline $\begin{array}{l}\text { - Loyal } \\
\text { - Patriotic } \\
\text { - Chain of } \\
\text { command is } \\
\text { essential } \\
\text { - Other } \\
\text { generations } \\
\text { might view them } \\
\text { as inflexible, } \\
\text { overcautious, not } \\
\text { technologically } \\
\text { savvy, even slow }\end{array}$ & $\begin{array}{l}\text { - Optimistic } \\
\text { - Question the } \\
\text { status quo } \\
\text { - Intensely } \\
\text { competitive } \\
\text { - Workaholic } \\
\text { - Social } \\
\text { - Other } \\
\text { generations } \\
\text { might view } \\
\text { them as self- } \\
\text { centered, } \\
\text { micromanagers } \\
\text {, even uptight }\end{array}$ & $\begin{array}{l}\text { - Independent } \\
\text { - Anti- } \\
\text { authority } \\
\text { - Computer } \\
\text { pioneers } \\
\text { - Smallest } \\
\text { generation; } \\
\text { competition } \\
\text { for them } \\
\text { - Other } \\
\text { generations } \\
\text { may view } \\
\text { them as } \\
\text { slackers, } \\
\text { cynical, } \\
\text { aloof, even } \\
\text { rude }\end{array}$ & $\begin{array}{l}\text { - Protection } \\
\text { and safety } \\
\text { are important } \\
\text { - Center of } \\
\text { "self-esteem" } \\
\text { movement } \\
\text { - Technologic- } \\
\text { ally savvy; } \\
\text { multitaskers } \\
\text { of highest } \\
\text { order } \\
\text { - Multicultural } \\
\text { and tolerant } \\
\text { of diversity } \\
\text { - Other } \\
\text { generations } \\
\text { may view } \\
\text { them as } \\
\text { needy, } \\
\text { indulged, } \\
\text { self- } \\
\text { absorbed, } \\
\text { naive, even } \\
\text { entitled }\end{array}$ \\
\hline
\end{tabular}

Figure 2. Generational characteristics, (Frances-Smith, 2004). 
Addressing the learning needs of the future workforce may be more important to focus on than investing in leadership development programs that fit the learning style of an outgoing labor force (Baird \& Fisher, 2005; Johnson \& Romanello, 2005; Wilson, 2004). This is perhaps one of the tradeoffs worth facing; conceding leadership development opportunities for the older generation of the workforce to build the infrastructure for the learning patterns of future managers. Nevertheless, a tremendous amount has been put into the structure of how the babyboomer generation learns and grows as a workforce. Research indicates that those competent and comfortable with virtual environments and are skilled in using technologies will be more effective in achieving virtual learning goals (Wan et al., 2012).

\section{METHODOLOGY}

Introduction. To determine the elements needed to transition leadership development to a virtual environment, I conducted a phenomenological qualitative study in the form of openended interviews with practitioners and scholars in executive leadership development, as well as members of the IC workforce that have participated in face-to-face leadership development courses. The goal of phenomenological research is to describe the meaning of a group of individuals' lived experience (Padilla-Díaz, 2015). In this section, I will describe the methodology used to gather this information, including subject descriptions, measurement procedures, research design, description of the procedures, and the data analysis implementation.

Method Rationale. The method used for this research included open-ended interview questions that were chosen to understand the needs of the IC workforce in the area of leadership development. Phenomenological research examines the lived experiences of groups of individuals (Padilla-Díaz, 2015). This method was chosen for this research to gain a better understanding of the effectiveness of pedagogical practices and techniques previously used in the context of the IC. Open-ended interview questions allowed for each participant to describe their needs and desires concerning leadership development. Once interviews were concluded, I then coded the data, with common themes emerging from the review (Creswell, 2009; Roberts, 2010). Among the workforce, and compared those themes with the recommendations leadership development scholars and practitioners.

Description of Subjects. The participants for this study were chosen because they represent a significant cross-section of the IC's demographics in experience, rank, and occupation. Experience reflects the length of service in years by the employee; rank reflects the employee's status in the organization's hierarchy. The workforce subjects for this study are taken from a variety of tradecrafts within the IC. To maintain the anonymity of the subjects, job titles and specific work rolls were not recorded in the interviews. Generic job functions have been assigned as a substitute. Those in the mission category are those that perform the unique function of their agency. Those with the support role are those that offer administrative or other professional duties not unique to their agency's particular mission. To create a larger sample, I then proceeded to solicit invitations to those in the IC that have participated in leadership development training. Fifty-four invitations were delivered. Out of the fifty-four invitations, ultimately ten subjects agreed to participate. Based on the findings of this research and the consistency of responses, I believe population saturation was achieved. 
Subjects in the leadership training scholars/practitioners group were identified as a sample of convenience based on current and past personal and business relationships with myself. An initial formal invitation was sent to 15 potential participants from the academic and scholarly field of leadership development, as well as those currently offering leadership development training. Out of these invitations, only one subject accepted the invitation. The subject went on to refer me to two other participants, creating a total of three scholarly/practitioner subjects. This form of sampling, the snowball strategy, often ensues once a study has already begun and occurs when the interviewer asks participants to recommend other potential interviewees. (Creswell, 2009; Roberts, 2010).

The first set of human subjects that participated in this study is anonymous members of the IC workforce that range from junior employees that are within their first five to ten years of their career, as well as upper-level management that have been in their careers for twenty or more years. Subjects from the Senior Executive Service were excluded from this study, as the Senior Executive Service currently uses a leadership development structure that is separate from the rest of the workforce.

The second category of interviewees came from those in academia that administer leadership development courses and have authored scholarly papers and books covering the field of leadership development. Subjects in this group were identified as a sample of convenience based on current and past personal and business relationships with myself, and my knowledge of their ongoing work and reputation on the research topic examined in this study.

Table 1

Description of Interviewees from the IC Workforce

\begin{tabular}{llll}
\hline \multicolumn{1}{c}{ Subject } & \multicolumn{1}{c}{ Experience } & \multicolumn{1}{c}{ Role } & Gender \\
\hline Subject 1 & 10-15 Years & Mission & Female \\
Subject 2 & 5-10 Years & Support & Male \\
Subject 3 & 15-20 Years & Mission & Female \\
Subject 4 & 25-30 Years & Support & Male \\
Subject 5 & 5-10 Years & Mission & Female \\
Subject 6 & 10-15 Years & Mission & Male \\
Subject 7 & 10-15 Years & Support & Male \\
& & & \\
\hline
\end{tabular}


Table 2

Description of Practitioners and Scholars Interviewees

\begin{tabular}{llll}
\hline Subject & $\begin{array}{l}\text { Leadership } \\
\text { Scholar? }\end{array}$ & Leadership Author & $\begin{array}{l}\text { Practitioner/ } \\
\text { Facilitator }\end{array}$ \\
\hline Subject 8 & 10-15 Years & Yes & Yes \\
Subject 9 & 5-10 Years & Yes & Yes \\
Subject 10 & 15-20 Years & Yes & No \\
& & & \\
\hline
\end{tabular}

Instrumentation. Data for this study was collected through personal interviews. Each subject that in the workforce category received the same questions, and the opportunity to clarify questions was provided. Subjects that were practitioners and scholars were also asked identical questions. There was no time limit given to answer each question. For those in the IC workforce category that were interviewed in person, no recording device was used due to the security regulations of the facilities where the interviews were conducted. After each question was answered, I restated the answer as recorded in writing, and the subject was asked to confirm that what was recorded was indeed what they had answered (Creswell, 2009; Bryant, 2004).

Table 3

Questions Asked to Subjects of the IC Workforce

\begin{tabular}{ll}
\hline Number & \multicolumn{1}{c}{ Question } \\
\hline 1 & $\begin{array}{l}\text { What motivates you to participate in leadership } \\
\text { development opportunities? }\end{array}$ \\
2 & $\begin{array}{l}\text { If you were given the opportunity to participate in a } \\
\text { leadership development course, offered virtually by } \\
\text { your agency, what elements or activities would need } \\
\text { to be included in the course to make it worth your } \\
\text { time? }\end{array}$ \\
\hline Question Number & Question \\
\hline 3 & $\begin{array}{l}\text { At the end of the course, what outcomes would you } \\
\text { need to observe to consider the course a success? }\end{array}$ \\
\hline
\end{tabular}


Table 4

Questions Asked to Subjects that are Practitioners and Scholars in Leadership

Development

\begin{tabular}{ll}
\hline Question Number & Question \\
\hline 1 & $\begin{array}{l}\text { If you were asked to consult a } \\
\text { government agency in transitioning } \\
\text { their leadership development program } \\
\text { from face-to-face to the virtual } \\
\text { environment, what recommendations } \\
\text { would you offer? }\end{array}$ \\
& $\begin{array}{l}\text { If your organization was asked to produce } \\
\text { a virtual leadership development course } \\
\text { for a government agency, how would you } \\
\text { approach that, meaning where would you } \\
\text { start? }\end{array}$ \\
& Would you measure success differently \\
& for a virtual leadership course as opposed \\
& to measuring success with a face-to-face \\
& course?
\end{tabular}

Data Analysis Plan. After the seven in person and three telephone interviews were conducted, I reviewed and typed the handwritten notes, and transcribed the audio recording of the phone interviews. I then examined the transcripts as a whole and made notes based on first impressions. I then read the transcript again, one-by-one in a more focused line-by-line reading, coding emerging themes by labeling relevant words, phrases, sentences, and sections. This coding was applied to elements of the interview based on my recognition that the topic or phrase was repeated because the interviewee stated its importance, the concept could be found in published literature, or it was related to a theory or concept reviewed in the study. These responses were coded as a conceptualization of underlying patterns (Creswell, 2009; Roberts, 2010).

Next, I read through all of the codes created and created new code by combining relevant responses. I then used these combined codes and labeled them in specific categories or themes. Once I labeled categories of the groups, connections between the themes were described. These categories and connections are considered the primary results of this study (Creswell, 2009). Because IC agencies executing a contract for virtual leadership development may need to 
evaluate and prioritize each element based on resources, a hierarchy was created among the categories.

Quality and Verification and Limitations. To further validate the findings of the study, I provided each interviewee a summary of the data collected in their interview. Each interviewee concurred with my interpretations. Based on review of the data by the interviewees, adjustments were made to clarify the need for continuous mentorship and continuous feedback (Creswell, 2009).

The primary limitation of the study is the small sample size. Having interviewed seven IC employees may limit the ability to generalize to the seventeen agencies that make up the IC. Also, the three scholar/practitioners represent a small sample size, though likely more generalizable based on the smaller pool of executives leading academic leadership development efforts.

\section{FINDINGS}

Summary and Presentation of the Findings. Through the interviews conducted, eight primary themes emerged as important to include in a virtual leadership development course. These eight themes include self-understanding, action learning, interaction, contextual, knowledge evaluations, follow-up, mentorships, and self-advancement. Throughout all of the interviews, no respondents expressed that they would not want to participate in a virtual leadership development course, and only one respondent suggested that a blended virtual and face-to-face learning environment would be preferred over strictly face-to-face or virtual. The themes that emerged from the data collection reflect what both leadership development consumers, as well as deliverers, believe to be important. The data are organized by the number of unique instances that each theme was discussed in the interviews.

Self-Understanding. In twenty-three separate instances, the interviewees expressed the need for leadership course elements that emphasized a greater understanding of self. For example, Interviewee 10 stated, "self-understanding is huge. Strengths, weaknesses, how to address challenges in neutral environment. It's good to have peers and veterans as a sounding board." The most common responses associated with self-understanding referenced the MyersBriggs Type Indicator tool, 360 assessments, and other generic references to self-assessments. On self-assessments, Interviewee 4 stated, "Something like MBTI or other assessment that really focuses on understanding yourself." Many other responses were not specific examples of tests or assessments, but directly stated the need for further self-understanding and knowledge. Multiple interviewees in response to separate questions repeated the theme of self-understanding, which also indicates a particular need. The theme of self-understanding was present in the responses from the practitioners and scholars, as well as interviewees that represent the IC workforce. Interviewee 1, a leadership scholar and practitioner stated that, "the most important component of any leader development program, whether it's face-to-face or online, is the opportunities for individuals to explore their greater inner knowledge, to increase their self-awareness about their core values, who they are as leaders, to explore reflective questions such as why do they lead". Self-understanding relates closely to the seven additional themes discussed in the following sections of this paper, as each theme could be considered a segment of self-understanding. Self- 
understanding is included as an individual theme due to the emphasis placed by the interviewees, as well as to create greater specificity within the remaining themes. For example, in action learning, there is a strong emphasis on what the manager is learning, as well as how they learn.

Action Learning. Marquardt (2004) describes action learning as a "development tool that simultaneously solves problems and develops leaders and teams." The primary focus of action learning is to place learning in real situations or simulations, to ask appropriate questions in that environment, and reflect on the learning experience. The interviewees of this study indicated in seventeen unique instances the need for some form of action learning. For example, Interviewee 1 stated, "And some of those high-impact leadership develop interventions include things like action learning components, so that [in] an online platform I would build an action learning experience for participants; whether that's an individual action learning activity or a team action learning activity, or both."

The most common responses included the need for simulations, scenario-based roleplaying activities, as well as how to deal with difficult situations in a safe practice environment. The other responses were thematically associated with action learning. For example, Interviewee 7 stated, "[I would like to experience] scenarios that we could work through. Kind of like labs" and Interviewee 5 stated that they would want to experience "some sort of team or role-playing activities that have scenario-based decision making." As previous research suggests, there are benefits in the use of action learning programs as a means "to develop specific, self-selected leadership skills, and acquire greater effectiveness in building teams and handling problems" (Raudenbush \& Marquardt, 2008).

Interaction. In sixteen separate instances, the interviewees stated the importance of interaction as an element of a virtual leadership development course. The interaction was separated from action learning as the responses for interaction include experiencing diversity, networking, and thoughtful dialogue as part of the course - as opposed to action learning, which emphasizes simulations. Previous research indicates that one of the major benefits of the virtual format relates to the ability to enable cross-cultural discussion and debate on ethical issues as they pertain to the contextual influences of the student's culture and environment (PainterMorland, Fontrodona, Hoffman, \& Rowe, 2003). There was also an element of comradery and support evident in the responses by those of the IC workforce. For example, Interviewee 8 stated, "Experience diversity and networking is [...] a motivator. It's good to be around peerspeople who are going through the same situations, and interact" and Interviewee 6 stated. "There needs to be an interactive element, not just watching recordings."

Context. As previous research indicates, there is a strong emphasis not only on what a student is learning but how they learn, as well as the context of the learning (Raudenbush \& Marquardt, 2008). There were thirteen unique instances where respondents indicated that a significant element of virtual leadership development in their organization should be context, meaning that it should be related to their occupation. For example, Interviewee 9 stated,

I've taken leadership development classes in the past where they work commercially driven scenarios that were not necessarily applicable to the government work roles that we are in. I would like to see some leadership development scenarios played out in the course that apply to everyday situations Government employees face. 
Several interviewees emphasized that it was important that the materials and exercises in a leadership development course be aligned to their profession, as well as their organization's mission. In other words, it was important for respondents that a course includes scenarios often faced in their day-to-day occupation. Interviewee 2 stated, "Context to me matters so much around leadership development. For whom, and what are their end goals for folks." As previous research indicates, effective strategies for learning in the virtual format involve conducting group exercises and role-playing that fit within specific objectives and contexts (Liebowitz, 2003).

Results on Knowledge Evaluations. Closely related to self-understanding, knowledge evaluations also provide an opportunity for the essential practice of reflection (Bos \& Shami, 2006). As stated by Interviewee 2, "I think survey [what] people already know. Developmentally or professional skills. All that knowledge comes into play."Also associated with feedback, a formative assessment in learning environments that allow learners to give and receive input on the progress of their learning, knowledge evaluations can provide benchmarks and updates on their progress (Espasa \& Meneses, 2009). Twelve times respondents expressed that knowledge evaluations were an essential element of leadership development. For example, Interviewee 1 states, "The first place I would begin is doing some surveys and questionnaires about what the particular audience thinks they need to know and be able to do well in their leadership. So, to try to get a sense of where the audience is and what the needs are." Knowledge evaluations differ from understanding oneself in that knowledge evaluations provide a snapshot of one's understanding on a certain topic (both before, during, and after a course), while self-understanding tools provide the learner with knowledge of strengths and weaknesses found within their personality and traits.

Results on Follow-up. There was strong response, ten unique instances, where interviewees believed that a learning system should offer support after the end of the course. This support may include some other elements discussed in this study, such as 360 assessments, knowledge tests, and interaction. As Interviewee 6 stated, "there should be an ongoing supporting framework." As previous research indicates, the virtual format relates to the ability to enable cross-cultural interaction on ethical issues as they pertain to the contextual influences of the student's culture and environment on and ongoing basis (Painter-Morland, Fontrodona, Hoffman, \& Rowe, 2003). Interviewee 1 stated, "the biggest advantage, I think, of an online platform is to continue to the participants learning, over time. Because if they are already accustomed to that kind of learning, and it is so much easier too, once a program ends formally, to continue to provide resources online or modules to alumni of programs and so forth." What differentiates follow-up from other elements discussed in this research is the long-term focus that allows learners to reflect and assess their knowledge once they have re-entered their work environments, and can then apply their knowledge and understanding to real circumstances.

Results on Mentorships. A significant characteristic that routinely appeared in interview responses was the need for mentorship opportunities. For example, Interviewee 5 stated, "I would also want to see some senior leaders participating for both their experiences and help." Seven unique instances mentorships were expressed as important. Additionally, Interviewee 1 stated it was important for participants to "find wise mentors that they'd be able to also reach out to virtually and continue their learning through role models and mentors as well. Previous research indicates that it is important is to place the learner real situations where they can ask 
appropriate questions, which mentors could be present to consult (Raudenbush \& Marquardt, 2008).

Being on the receiving end of mentorships was not the individual approach in the responses. In one instance, an interviewee stated that it is important to be a mentor, not merely a mentee. For example, Interviewee 9 stated, "the people side of things is still important and the soft skills too. It's also important to meet others, mentor others, and view others in different leadership development stages."

Results on Self-Advancement. The final characteristic that appeared in a significant number of responses was the theme of self-advancement. Two interviewees stated directly that career advancement was a primary factor in their participation in leadership development, while several others inferred both career and other types of growth. For example, Interviewee 5 stated that they are motivated to participate in leadership development courses "primarily career advancement. There's a need for leadership skills at the next level." The two interviewees that that cited career advancement directly, interviewees 5 and 6, both likely fit into the millennial generation based on length of professional experience. This aligns with previous research that suggests the perceptions millennial generation is focused on the self (Djamasbi, Siegel, Skorinko, and Tullis, 2011).

Analysis and Proposed Solution. The results of the findings of this study suggest that the IC workforce requires a highly interactive, reflective, and continuous leadership development experience. Virtual leadership development by an IC organization should include these themes. Absent from the responses is the desire for passive participation such as lectures or videos. What is more, the respondents emphasized a desire to learn and grow in their personal leadership development experience. This demonstrates the requirement to maintain a personal element to a virtual leadership development course.

The strong response for follow-up, mentorships, and networking demonstrates the need for an ongoing leadership development support structure, not merely a one-time resource or experience. This, along with the necessity of knowledge tests and evaluations, demonstrates the desire IC employees have for actual learning and self-improvement in the area of leadership development.

Two respondents in the interviews indicated that leadership development was important in advancing their careers, and that promotion panels look at résumés to determine if leadership development experiences are present. I did not include these answers in the primary themes, as only two interviewees indicated career advancement as a factor. However, other interviewees may believe that career advancement is a motivating factor for participating in leadership development, yet respondents may have decided not to discuss career advancement due to a negative perception of their motives. Because of the emphasis that the two respondents placed on career advancement, feedback was included in the self-advancement data.

The data gathered adds validation to several assertions made in previous research discussed earlier in this paper in the literature review. Self-understanding, action learning, knowledge evaluations, mentorships, and follow-up can are all elements needed for virtual 
leadership development that incorporates feedback. These characteristics of virtual leadership development, as Espasa and Meneses (2009) explain, should identify the presence of feedback, characterize feedback, and explore relationships between feedback and results. In addition to assertions made concerning feedback, the data gathered for this research also validates Liebowitz's (2003) belief that group exercises and role-playing should be central to virtual learning -affirming the need for action learning as a characteristic of virtual leadership development. Action learning, which was a significant response given by interviewees, also affirms Wedig's (2010) suggestion that managers often are passive and lack energy in leadership development courses, and that a course should have characteristics that are focused and hold the attention of the participants.

Potential Barriers and Obstacles to Proposed Solution. Although mentorship is one of the eight essential elements found in this study and previous research (Raudenbush \& Marquardt, 2008), many of the potential barriers rest with those that reside in the Senior Executive Service (SES). Because members of the SES are the decision makers when it comes to major program and budget changes, and this change would have the most perceived negative impact on that group, creating buy-in from the SES corps will likely be a challenge. Although the SES would present a potential barrier, the flexibility of virtual leadership development would be a benefit, as arranging traditional senior executive leadership development can be difficult, and often takes managers away from their offices and programs for significant amounts of time. This flexibility though could also present a barrier, as managers may be seeking an opportunity to leave the distractions and stresses of their home offices to focus solely on their leadership training. Additionally, SES executive training is often considered a rite of passage for those entering the highest ranks of public service. There may be a perception by those entering SES positions that their ascension was not as prestigious because they did not attend the notable leadership institutions attended by their predecessors.

Resistance to virtualization may also prove to be a barrier to achieving this form of leadership development within the government ranks. Although research has demonstrated that multiple generations are suited for virtual learning (Djamasbi, Siegel, Skorinko, and Tullis, 2011), the change of long-standing practices in leadership development may be difficult for many. This could be accompanied by a perceived loss of funds, as funds would likely be diverted from traditional programs.

In short, many of the barriers and obstacles in implementing virtual leadership development concern institutional norms and resistance to change. There are potential technology obstacles that will be encountered, as there would be with the deployment of any new IT service, but these obstacles are not likely to prevent the solution from being implemented.

Recommendations for Further Research. This study has focused largely on what is needed in a virtual leadership development course for the IC. An internal government study is required to assess the cost-savings or cost-avoidance associated with such an effort. Because the budgets of individual intelligence agencies are not available to the public, this future research must be completed or facilitated by the government. 
Other large agencies outside of the IC could benefit from this study. There may be broad applicability if other agencies are operating in a highly selective, face-to-face leadership development model. There may also be agencies that are not engaged in leadership development, either face-to-face or virtual, that could implement a phased virtual model. This study would also benefit from future discussions with major private organizations that provide leadership development services. Understanding their experiences, operational models, and pedagogy would offer insight into how virtual leadership development could be implemented.

Earlier research was cited in this study that suggests simulation is the best option to achieve desired levels of learning in leadership development (Wedig, 2010). To determine the full applicability of this study as it relates to the government leadership development environment similar courses must be taught with and without the use of simulations to understand if this is a critical factor to student learning success. If further proven that virtual asynchronous simulation is preferred in such environments, it may also be preferred in organizational training.

The focus of this study has been a shift in the delivery of large-scale leadership development. Future research should be conducted to determine if this study has applicability on a small scale for smaller government agencies. Because there may be significant initial up-front costs associated with implementing virtual leadership development, more research is warranted to determine the cost savings for smaller organizations. 


\section{References}

Allen, A. (2008). The virtuous spy: Privacy as an ethical limit. The Monist, 91(1), 3-

22. Retrieved January 20, 2015, from http://www.jstor.org.cuhsl.edu/stable/27904063

Bryant, M. (2004). The portable dissertation advisor. Thousand Oaks, CA: Corwin Press.

Baird, D., \& Fisher, M. (2005). Online learning design that fosters student support, selfregulation, and retention. Campus-Wide Information Systems: The International Journal of Information and Learning Technology, 22(2). London, U.K. Retrieved January 20, 2015 from https://pantherfile.uwm.edu/simonec/public/Motivation\%20retention\%20articles/Articles/ Fisher_OnlineLearningDesign.pdf

Ball, J., \& Rusche, D. (2013, June 6). NSA prism program taps in to user data of Apple, Google and others. The Guardian. Retrieved January 20, 2015, from http://www.guardian.co.uk/world/2013/jun/06/us-tech-giants-nsa-data

Bartol, K, \& Locke, E. (2006). Empowering Leadership in Management Teams: Effects on Knowledge Sharing, Efficacy, and Performance. Academy of Management Journal. 49(6), 1239-1251. Retrieved January 20, 2015, from http://www.jstor.org/stable/20159830

Bos, N., \& Shami, N. S. (2006). Adapting a face-to-face role-playing simulation for online play. Educational Technology Research and Development, 54(5), 493-521. Retrieved from http://link.springer.com.cuhsl.edu/article/10.1007/s11423-006-0130-z

Bosserman, B. (2011). The national security implications of a balanced budget amendment. Center for Strategic and International Studies. Retrieved January 20, 2015, from http://csis.org/files/publication/111110_Balanced Budget Amendment.pdf

Botsch, R., \& Botsch, C. (2012). Audiences and outcomes in online and traditional American government classes revisited. PS: Political Science and Politics, 45(3), 493500. Retrieved February 19, 2015, from http://www.jstor.org.cuhsl.edu/stable/41691365

Burden, B., \& Hillygus, S. (2009). Polls and elections: Opinion formation, polarization, and presidential reelection. Presidential Studies Quarterly, 39(3), 619-635. Retrieved January 19, 2015, from http://www.jstor.org.cuhsl.edu/ stable/41427381

Center for Leadership Development. (n.d.). Schedule at a Glance. Retrieved February 17, 2015, from https://leadership.opm.gov/courses.aspx

Clapper, J. R. (2013). Intelligence Community information technology enterprise strategy, 20122017. Office of the Director of National Intelligence, Office of the Chief Information Officer. Retrieved January 20, 2015, from http://www.dni.gov/files/documents/IC_ITE_Strategy.pdf 
Clark, L. (2010). Statutory struggles of administrative agencies: The Director of National Intelligence and the CIA in a post-9/11 world. Administrative Law Review, 62(2), 545-572. Retrieved January 19, 2015, from http://www.jstor.org.cuhsl.edu/stable/40712120

Creswell, J. (2009). Research design: Qualitative, quantitative, and mixed method approaches (3rd ed.). Thousand Oaks, CA: Sage.

Director of Central Intelligence. (2002). Physical Security Standards for Sensitive Compartmented Information Facilities (Directive No. 6/9). Retrieved from http://fas.org/irp/offdocs/dcid6-9.pdf

Djamasbi, S., Siegel, M., Skorinko, J., \& Tullis, T. (2011). Online viewing and aesthetic preferences of generation $\mathrm{Y}$ and the baby boom generation: Testing user web site experience through eye tracking. International Journal of Electronic Commerce, 15(4), 121-158. Retrieved January 20, 2015, from http://www.jstor.org.cuhsl.edu/stable/41300718

Driscoll, A., Jicha, K., Hunt, A., Tichavsky, L., \& Thompson, G. (2012). Can online courses deliver in-class results?: A comparison of student performance and satisfaction in an online versus a face-to-face introductory sociology course. Teaching Sociology, 40(4), 312-331. Retrieved January 20, 2015, from http://www.jstor.org.cuhsl.edu/stable/41725516

Espasa, A., \& Meneses, J. (2010). Analysing feedback processes in an online teaching and learning environment: An exploratory study. Higher Education, 59(3), 277-292. Retrieved January 20, 2015, from http://dx.doi.org/10.1007/s10734-009-9247-4

Godfrey, E., \& Jacobs, A. (1978). Ethics and Intelligence. Foreign Affairs, 56(4), 867875. Retrieved January 18, 2015, from http://www.jstor.org.cuhsl.edu/stable/20039922

Goldman, J. (2006). Ethics of spying: A reader for the intelligence professional. Lanham, MD: Scarecrow Press.

Gorman, S., \& Entous, A. (2013, October 28). Obama unaware as U.S. spied on world leaders: Officials. The Wall Street Journal. Retrieved January 20, 2015, from http://www.wsj.com/articles/SB10001424052702304470504579162110180138036

Hatfield, E. L. (2008). Finding leaders: Preparing the intelligence community for succession management. Informally published manuscript, Center for Strategic Intelligence Research, National Defense Intelligence College, Washington, D.C., Retrieved from http://www.au.af.mil/au/awc/awcgate/dia/ndic_finding_leaders.pdf

Herman, M. (1999). Intelligence services and ethics in the new millennium. Irish Studies in International Affairs, 10, 249-265. Retrieved January 20, 2015, from http://www.jstor.org.cuhsl.edu/stable/30001902 
Johnson, S., \& Romanello, M. (2005). Generational diversity: Teaching and learning approaches. Nurse Educator, 30(5), 212-216. Retrieved January 20, 2015, from http://www.chw.org/ /media/Files/Medical Professionals/Nursing Students/generational diversity teaching and learning approaches.pdf

Kim, Y. (2004). Online education tools. Public Performance \& Management Review, 28(2), 275280. Retrieved January 19, 2015, from http://www.jstor.org.cuhsl.edu/stable/3381065

Kingma, B., \& Keefe, S. (2006). An analysis of the virtual classroom: Does size matter? Do residencies make a difference? Should you hire that instructional designer? Journal of Education for Library and Information Science, 47(2), 127-143. Retrieved January 19, 2015, from http://www.jstor.org.cuhsl.edu/stable/40324327

Lerman, R., \& Schmidt, S. (n.d.). Demographic change and the future workforce. Retrieved January 20, 2015, from

http://www.dol.gov/dol/aboutdol/history/herman/reports/futurework/conference/trends/tre ndsI.htm

Liebowitz, J. (2003). Teach people skills totally online? College Teaching, 51(3), 82-85. Retrieved January 20, 2015, from http://www.jstor.org.cuhsl.edu/stable/27559140.

Lowenthal, M. (2000). Intelligence: From secrets to policy (p. 65). Washington, DC: CQ Press.

Lowenthal, M. (2011). Intelligence: From secrets to policy (5th ed., p. 32). Washington, DC: CQ Press.

Marquardt, M. (2004). Optimizing the power of action learning solving problems and building leaders in real time (p. 3). Palo Alto, Calif.: Davies-Black.

McIntosh, D. (2015, March 18). Vendors of Learning Management and E-learning Products. Retrieved April 3, 2015, from http://www.trimeritus.com/vendors .pdf

Monahan, T. (2011). Surveillance as cultural practice. The Sociological Quarterly, 52(4), 495508. Retrieved January 20, 2015, from http://www.jstor.org.cuhsl.edu/stable/23027562.

Myers, K., \& Sadaghiani, K. (2010). Millennials in the workplace: A communication perspective on millennials' organizational relationships and performance. Journal of Business and Psychology, 25(2), 225-238. Retrieved January 20, 2015, from http://www.jstor.org.cuhsl.edu/stable/40605781

National Security: An Overview of Professional Development Activities Intended to Improve Interagency Collaboration. (2010). Retrieved January 20, 2015, from http://www.gao.gov/new.items/d11108.pdf 
Office of the Director of National Intelligence. (2006). The U.S. Intelligence Community's five year human capital plan. Retrieved February 17, 2015 from https://www.fas.org/irp/dni/humancapital.pdf

Office of the Director of National Intelligence, (2008). IC 2008 employee climate survey: Summary of results summary of results. Retrieved January 19, 2015 from http://www.hsdl.org/?view\&did=37516

Padilla-Díaz, M. (2015). Phenomenology in Educational Qualitative Research: Philosophy as Science or Philosophical Science? International Journal of Educational Excellence, 1(2), 101-110. doi:10.18562/ijee.2015.0009

Painter-Morland, M., Fontrodona, J., Hoffman, W., \& Rowe, M. (2003). Conversations across continents: Teaching business ethics online. Journal of Business Ethics, 48(1), 75-88. Retrieved January 20, 2015, from http://www.jstor.org.cuhsl.edu/stable/25075166.

Patel, C., \& Patel, T. (2006). Exploring a joint model of conventional and online learning systems. E-Service Journal, 4(2), 27-46. Retrieved January 20, 2015, from http://www.jstor.org.cuhsl.edu/stable/ 10.2979/ESJ.2006.4.2.27

Perry, M. (1995). The constitution in the courts: Law or politics? New York: Oxford University Press.

Pellerin, C. (2013, September 11). Intel Officials Announce Community IT Enterprise Milestone. American Forces Press Service. Retrieved January 20, 2015, from http://www.defense.gov/news/newsarticle.aspx?id=120755

Raines, C. (2003). Connecting generations: The sourcebook for a new workplace. Menlo Park, Calif.: Crisp Publications.

Randol, M. (2010). The Department of Homeland Security intelligence enterprise operational overview and oversight challenges for Congress, Congressional Research Service, Washington, D.C.

Raudenbush, L., \& Marquardt, M. (2008). Growing leaders at the U.S. Department of Agriculture: A case study of leadership development using action learning. Public Administration Quarterly, 32(2), 147-173. Retrieved from http://www.jstor.org/stable/41288311

Roberts, C. (2010). The dissertation journey: A practical and comprehensive guide to planning, writing, and defending your dissertation (2nd ed.). Thousand Oaks, Calif.: Corwin Press.

Schwab, B. (1996). A note on ethics and strategy: Do good ethics always make for good business? Strategic Management Journal. 17(6), 499-500. Retrieved January 19, 2015 from http://www.jstor.org/stable/2486930 
The Good, the Bad, and Their Corporate Codes of Ethics: Enron, Sarbanes-Oxley, and the Problems with Legislating Good Behavior. (2003). The Harvard Law Review, 116(7), 2123-2141. Retrieved February 17, 2015, from http://www.jstor.org.cuhsl.edu/stable/1342755

Thomas, T., Schermerhorn, Jr, J., Dienhart , J., \& Bartles, D. (2004). Strategic leadership of ethical behavior in business [and executive commentary]. The Academy of Management Executive, 18(2), 56-68. Retrieved January 19, 2015 from http://www.jstor.org/stable/4166062

Walsh, J. (2007). Defection and hierarchy in international intelligence sharing. Journal of Public Policy, 27(2), 151-181. Retrieved January 20, 2015, from http://www.jstor.org.cuhsl.edu/stable/40072019

Wan, Z., Compeau, D., \& Haggerty, N. (2012). The effects of self-regulated learning processes on e-learning outcomes in organizational settings. Journal of Management Information Systems, 29(1), 307-340. Retrieved January 20, 2015, from http://www.jstor.org.cuhsl.edu/stable/41713877

Weakliem, D., \& Finkel, S. (2006). Morale and workplace performance. Work and occupations, 33(3), 335-361. Retrieved January 20, 2015, from http://wox.sagepub.com/content/33/3/335.short

Wedig, T. (2010). Getting the most from classroom simulations: Strategies for maximizing learning outcomes. PS: Political Science \& Politics, 43(3), 547-555. Retrieved January 20, 2015, from http://www.jstor.org.cuhsl.edu/stable/25699364

Wilson, E. (2004). Leadership in the digital age. In G. Goethals, G. Sorenson, \& J. Burns (Eds.), Encyclopedia of leadership. (pp. 859-862). Thousand Oaks, CA: Sage. doi: http://dx.doi.org/10.4135/9781412952392.n199

Ya Ni, A. (2013). Comparing the effectiveness of classroom and online learning: Teaching research methods. Journal of Public Affairs Education, 19(2), 199- 215. Retrieved February 25, 2015, from http://www.jstor.org.cuhsl.edu/stable/23608947

\section{Author Biography}

Dr. Jacob R. Jenkins (Jacob.Jenkins@georgetown.edu) is the Executive Director of Executive Education at Georgetown University's McCourt School of Public Policy. His teaching and scholarship focuses on the training and development of the federal workforce. Prior to Georgetown, he served as Director of George Mason University's Mason Institute for Leadership Excellence. From 2003-2015 he held appointments at the U.S. Department of Justice and the National Geospatial-Intelligence Agency. 